ISSN 0103-8478

\title{
Levantamento de Meloidogyne exigua na cultura da seringueira em São José do Rio Claro, MT, Brasil
}

\author{
Meloidogyne exigua survey on rubber tree in São José do Rio Claro, MT, Brazil
}

\author{
Eduardo Roberto de Almeida Bernardo ${ }^{1}$ Jaime Maia dos Santos $^{2}$ \\ Ricardo Adaime da Silva ${ }^{3}$ Daniel Cassetari Neto ${ }^{4}$ Suzana Souza dos Santos ${ }^{5}$ \\ Leila Delmadi ${ }^{6}$ Vander de Freitas Rocha $^{7}$
}

\begin{abstract}
Este trabalho foi realizado com o objetivo de efetuar um levantamento da ocorrência de Meloidogyne exigua em seringueira em São José do Rio Claro, MT. Foram amostradas 191 propriedades agrícolas, totalizando cerca de 18.000ha. Os nematóides foram identificados no Laboratório de Nematologia do Departamento de Fitossanidade da FCAV/UNESP, em Jaboticabal, SP. Foram encontrados niveis populacionais de $\boldsymbol{M}$. exigua entre 0 e 61.824 juvenis $/ 5 g$ de raizes.
\end{abstract}

Palavras-chave: nematóide das galhas, Meloidogyne exigua, Hevea brasiliensis, Botryodiplodia theobromae.

\section{ABSTRACT}

This study was carried out aiming to evaluate the Meloidogyne exigua occurrence on rubber tree in São José do Rio Claro, MT, Brazil. One hundred ninety one agriculture holdings were sampled, totalizing around 18000ha. The nematodes were identified in the Nematology Laboratory, Department of Fitossanidade, FCAV/UNESP, Jaboticabal, SP. Population levels of M. exigua between 0 and 61824 juveniles $/ 5 \mathrm{~g}$ of roots were observed.

Key words: root-knot nematode, Meloidogyne exigua, Hevea brasiliensis, Botryodiplodia theobromae.

\section{-NOTA-}

${ }^{1}$ Engenheiro Agrônomo, Mestrando em Agronomia, Departamento de Fitossanidade, Faculdade de Ciências Agrárias e Veterinárias (FCAV), Universidade Estadual Paulista (UNESP), Via de Acesso Professor Paulo Donato Castellane, s/n, 14880-900, Jaboticabal - SP. E-mail: erabernardo@hotmail.com. Autor para correspondência.

${ }^{2}$ Engenheiro Agrônomo, Doutor em Fitopatologia, FCAV, UNESP.

${ }^{3}$ Engenheiro Agrônomo, Doutorando em Agronomia, FCAV, UNESP.

${ }^{4}$ Engenheiro Agrônomo, Doutor, Universidade Federal do Mato Grosso.

${ }^{5}$ Engenheiro Florestal, Universidade Federal de Viçosa.

${ }^{6}$ Engenheiro Florestal, Mestrando em Agricultura Tropical, UFMT.

${ }^{7}$ Engenheiro Agrônomo, Mestrando em Agricultura Tropical, UFMT. 
absorção de água e nutrientes. Este nematóide dificilmente acarreta a morte das plantas, no entanto, atua como fator predisponente à ação de fungos, sendo as galhas sempre acompanhadas de extensas áreas necrosadas (SANTOS et al., 1992).

Este trabalho teve o objetivo de efetuar um levantamento da ocorrência de $\boldsymbol{M}$. exigua em áreas cultivadas com $\boldsymbol{H}$. brasiliensis, no município de São José do Rio Claro, MT. Durante o ano de 1998 foram realizadas amostragens do nematóide em diligências financiadas pela Delegacia Federal de Agricultura, Setor de Sanidade Vegetal do Ministério da Agricultura de Mato Grosso, coordenadas pela Estação de Avisos Fitossanitários (EAF), sediada no referido município. Foram amostradas 191 propriedades agrícolas, totalizando cerca de 18.000 ha de seringueira. Em cada propriedade, foram coletadas amostras de raízes $(20 \mathrm{~g})$, conforme TIHOHOD (2000), e marcadas as coordenadas geográficas por meio de um aparelho GPS (Global Position System). Foi calculada a distância de cada propriedade em relação à sede da EAF, encarregada de prestar assistência técnica e locar máquinas e implementos agrícolas aos produtores da região. As amostras foram acondicionadas em sacos de plástico, posteriormente fechados, identificados (local, data e proprietário) e enviados ao laboratório da EAF.

$$
\text { Para a }
$$

Tabela 1. Quantidade média de nematóides por $5 \mathrm{~g}$ de raízes em relação à distância das propriedades ao referencial (EAF). São José do Rio Claro, MT. 1998.

\begin{tabular}{ccccc}
\hline $\begin{array}{c}\text { Distância } \\
(\mathrm{Km})\end{array}$ & $\begin{array}{c}\text { Número de } \\
\text { amostras }\end{array}$ & $\begin{array}{c}\text { Distância média } \\
(\mathrm{Km})\end{array}$ & $\begin{array}{c}\text { Quantidade média de } \\
\text { nematóides/5g de raízes }\end{array}$ & $\begin{array}{c}\text { Amplitude } \\
\text { populacional }\end{array}$ \\
\hline 0 a 10 & 131 & 6,39 & $11.422,90$ & $(96-61.824)$ \\
10 a 20 & 78 & 14,71 & $7.511,38$ & $(48-53.760)$ \\
20 a 35 & 73 & 26,74 & $4.732,93$ & $(0-51.840)$ \\
\hline
\end{tabular}

tivamente. Populações superiores a 50.000 juvenis $/ 5 \mathrm{~g}$ de raízes foram encontradas em $2 \%$ das amostras. As plantas atacadas exibiam severos sintomas da doença, com acentuada formação de galhas nas raízes. Deve-se considerar que, além do dano direto nas raízes, decorrentes da intensa formação de galhas, este nematóide atua como fator predisponente à ação do fungo oportunista Botryodiplodia theobromae. Este fungo usualmente infecta plantas sob estresse e causa xa (SANTOS et al., 1992; SANTOS, 1995). O clone IAN 717 é o mais cultivado na região, sendo também o que exibe os sintomas mais precocemente, demonstrando maior susceptibilidade.

Os maiores índices populacionais de $\boldsymbol{M}$. exigua foram encontrados nas propriedades mais próximas à EAF, chegando a 61.824 juvenis $/ 5 \mathrm{~g}$ de raízes (Tabela 1). Tais índices provavelmente se devam a um maior trânsito de implementos agrícolas contaminados entre as propriedades, principalmente grades. Tais equipamentos, de uso comunitário, às vezes circulavam em mais de uma propriedade por dia, não sendo devidamente lavados para a retirada de solo aderente. seca descendente, tratando-se de uma doença comple- nematô dos

raízes, foi utilizada a técnica do liqüidificador aliada à centrifugação em solução de sacarose mais caolim (COOLEN \& D'HERDE, 1972). A estimativa da população de juvenis (J2) de M. exigua foi realizada com o auxílio de lâmina para contagem de Peters (TIHOHOD, 2000). Os nematóides foram identificados no Laboratório de Nematologia do Departamento de Fitossanidade da FCAV/UNESP, em Jaboticabal, $\mathrm{SP}$, por meio de microscopia ótica e eletrônica de varredura. Juvenis (J2) e machos do nematóide foram processados para microscopia eletrônica de varredura, segundo a técnica de EISENBACK \& HIRSCHMANN (1981). O padrão perineal foi preparado conforme SANTOS \& MAIA (1996).

Das amostras analisadas, $47 \%$ apresentaram até 1.000 juvenis $/ 5 \mathrm{~g}$ de raízes. Em $21 \%$ e $30 \%$ das amostras, foram encontradas populações entre $1.001 \mathrm{a}$ 10.000 e 10.001 a 50.000 juvenis $/ 5 \mathrm{~g}$ de raízes, respec-

Isso corrobora a afirmação de SHARMA et al. (1992), de que a gradagem favorece a dispersão e o aumento do nível de infestação do nematóide. Por tratar-se de uma cultura perene, a possibilidade de dispersão do nematóide preocupa, visto que foram encontradas propriedades ainda isentas do nematóide.

Com base no levantamento realizado, podese concluir que M. exigua está amplamente distribuído no município de São José do Rio Claro, MT, e que os maiores índices populacionais são encontrados nas propriedades mais próximas à Estação de Avisos Fitossanitários.

\section{REFERÊNCIAS BIBLIOGRÁFICAS}

AGRIANUAL 2001. Anuário da Agricultura Brasileira. São Paulo : FNP Consultoria \& Comércio, 2001. 545p.

COOLEN, W.A.; D'HERDE, C.J. A method for the quantitative extraction of nematodes from plant tissue. Ghent : State Agricultural Centre, 1972. 77p.

Ciência Rural, v. 33, n. 1, jan-fev, 2003. 
EISENBACK, J.D.; HIRSCHMANN, H. Identification of Meloidogyne species on the basis of head shape and stylet morphology of the male. Journal of Nematology, Athens, v.13, p.513-521, 1981.

SANTOS, J.M. dos. Meloidogyne exigua e Botryodiplodia theobromae, principais componentes bióticos de uma doença complexa da seringueira em Mato Grosso. Fitopatologia Brasileira, Brasília, v. 28, p.341, 1995.

SANTOS, J.M. dos et al. Meloidogyne exigua, sério patógeno da seringueira nas plantações. In: Michelin, em Rondonópolis, MT.
In: CONGRESSO BRASILEIRO DE NEMATOLOGIA, 1992 Lavras, MG. Anais... Lavras : Sociedade Brasileira de Fitopatologia, 1992. V. 17, p.75.

SANTOS, J.M. dos; MAIA, A.S. Uma nova técnica para documentação do padrão perineal de Meloidogyne spp. ao microscópio eletrônico de varredura. Fitopatologia Brasileira, Brasília, v.21, p.418, 1996.

SHARMA, R.D. et al. Efeitos de práticas culturais na incidência de Meloidogyne sp, em seringueira de cultivo. Fitopatologia Brasileira, Brasília, v.17, n.2, p.226, 1992.

TIHOHOD, D. Nematologia agrícola aplicada. 2 ed. Jaboticabal: FUNEP, 2000. 473p. 